\title{
Time-Space Utopian Model as a Critical Method of Sociology: A Book Review of Utopia Method Vision
}

\author{
Wanting Li \\ Beijing Language and Culture University, Beijing, China \\ Email: bonnielibj@hotmail.com
}

How to cite this paper: Li, W. T. (2021). Time-Space Utopian Model as a Critical Method of Sociology: A Book Review of Utopia Method Vision. Open Journal of Social Sciences, 9, 65-73.

https://doi.org/10.4236/jss.2021.912005

Received: November 14, 2021

Accepted: December 4, 2021

Published: December 7, 2021

Copyright ( 2021 by author(s) and Scientific Research Publishing Inc. This work is licensed under the Creative Commons Attribution International License (CC BY 4.0).

http://creativecommons.org/licenses/by/4.0/ (c) (i) Open Access

\begin{abstract}
Utopia as a method of sociology, has been identified as a proper and distinctive device for analyzing social structures and proposing social solutions to a better future. Since 2000, there has been an increasing attention to the function of Utopia. To discuss this topic, twelve well-known scholars in utopian studies participate in a two-year research seminar and contribute their perspectives of utopian method in the book Utopia Method Vision: The Use Value of Social Dreaming. This book provides a new sense of utopia's time and space nature but not a time-space utopia method. To fill in the gap, this study will propose a time-space utopian model after devising space and time models respectively through the method Bricolage. The products will contribute to the systematic understanding of utopia method in a time-space dimension, thus promoting a visualized time-space utopia model as a critical method of sociology.
\end{abstract}

\section{Keywords}

Utopia Method Vision, Utopia Method, Bricolage, Space Dimension, Time Dimension

\section{Introduction}

The book Utopia Method Vision: The Use Value of Social Dreaming (2007) is the first and the most representative one in utopian method field. Except for this book, the only work focuses on utopian method is Ruth Levitas's (2013) Utopia as Method: The Imaginary Reconstitution of Society whose argument has been mentioned in Utopia Method Vision 6 years ago. Moreover, this book is contributed by twelve international and renowned scholars in utopian studies includ- 
ing Tom Moylan, Raffaella Baccolini, Ruth Levitas, etc. Although coming from different disciplines and national traditions, they all concern about utopia's functions and share their perspectives of different utopian methods in this book.

However, papers in this book have been almost discussed separately rather than in a whole. Only Michael Gardiner reviewed Utopia Method Vision in a holistic way. Although he discusses utopia methods involved in this book, he fails to develop a systematic utopia method based on them.

This paper aims to develop a time-space utopia method through reviewing Utopia Method Vision. First, as utopia displays a desire of constructing a better society in the future, time and space are two main features of utopia as well as utopia method. Thus, concerning time-space dimension is essential to make utopia method more applicable. In addition, the relationships between utopia and time and space are emphasized in this book but not synthesized in a utopian method.

The time-space utopia method will display the achievement of utopia methods proposed in this book in a holistic and systematic way. Additionally, the product of this review will contribute to a time-space utopia method of sociology.

\section{Methodology}

To achieve the aims, bricolage as an approach will be employed in this research. The word bricolage comes from French, which refers to "a handyman or a handywoman who uses the tools available to complete a task" (qtd. in p. 418). The definition implies that bricolage is a tool synthesized by some other diverse tools. Since utopia itself is also a tool, the aimed utopian model can be regarded as a synthesized tool. Thus, bricolage can be abstracted as the method of synthesizing.

Besides, the utopia's process of synthesizing is critical. First, the utopian method itself is of ever-evolving criticality which avoids blueprints and allows for changes. Besides, "inquiry that aspires to the name critical must be connected to an attempt to confront structures of oppression" (Kincheloe et al., 2017: p. 421). Bricolage is an innovative tool employed in critical inquires consistent with the utopian method's essential part.

Furthermore, utopia is typical of "omnivorous multidisciplinary" (Sargisson, 2007: p. 1), which requires a tool "beyond the blinders of particular disciplines" (Kincheloe et al., 2017: p. 431). As Moylan mentions, "the development of the utopian field has been a collective improvisation on a series of overlapping themes, perhaps like a form of jazz" (qtd. in Levitas, 2007: p. 48). Bricolage is qualified since it can realize an eclectic process (Kincheloe et al., 2017).

Additionally, "bricolage implies the fictive and imaginative elements of the presentation of all formal research" (Kincheloe et al., 2017: p. 431). This feature is also in step with the utopia vision.

In a more micro aspect, the process of bricolage is applied through tinkering. "This tinkering is a high-level cognitive process involving construction and reconstruction, contextual diagnosis, negotiation, and readjustment" (p. 433). This 
process indicates the active construction rather than passive acceptance of "correct".

\section{Utopia Model of Space-Dimension}

Utopia is a spatial concept, and a utopia model can be devised via spatial thinking. Illuminated by Louis Marin (1984)'s concept of figuration, which represents a schematizing or "pre-conceptual" way of thinking (Wegner, 2007: p. 115), Philip Wegner (2007) claims utopia is an approach to display history and processes of a particular age and suggests using spatial thinking through "architectural drawing, a mapping, itinerary, or script" (Wegner, 2007: p. 119). The mode of thinking is settled, the framework and elements remain ambiguous.

Ruth Levitas (2007) identifies a sociology model called Imaginary Reconstitution of Society (IROS) method that contributes to the unambiguity of utopian spatial thinking. Since it explores "how society works as systems and thus how their characteristics connect up" (Levitas, 2007: p. 60). IROS method is composed of three modes which construct this model from three perspectives.

The first is an archeological mode that aims at uncovering and reconstructing the utopian fragments "embedded in political programs, social and economic policies" (Levitas, 2013: p. 153). I interpret this mode as "house mode", since it displays a house structure or external environment of a society. The functions of social, political, and economic policies in this "house" should be figured out.

Social policies are based on the expectant society's whole picture, which is an abstract idea and can be visualized as a cloud or a flash. After the ideal society is settled, political relations are constructed to sustain and economic ones to support it (Levitas, 2013). Thus, in the "house mode", political policies compose frameworks or steel bars of the house (see Figure 1), and economic policies are cement to make the structure stronger (the blue parts in Figure 1).

Since this model was proposed in 2007, some particular aspects it mentions can be transformed with time. However, the three perspectives, including political programs, social and economic policies, can be considered primary concerns in the house mode or the archeological mode, which stimulates an external environment of residents.

Any proposal of a utopian future aims to explore what is good for their citizens and how to make them happy. Thus, an ontological mode is discussed in the following part. The central point of this mode lies in the claims of "who we are and who we might be or should be" (Levitas, 2013: p. 196) to realize human flourishing, happiness, and well-being.

The first claim that "what human beings are" refers to a view of human nature. "Human nature is historically and socially determined and variable" (Levitas, 2013: p. 175) but it does not mean human nature is "infinitely malleable" (Levitas, 2013: p. 175). This argument implicates that human nature is composed of invariable and variable parts. The invariable ones are not absolutely stable, but need much more time to change than the variable ones. 


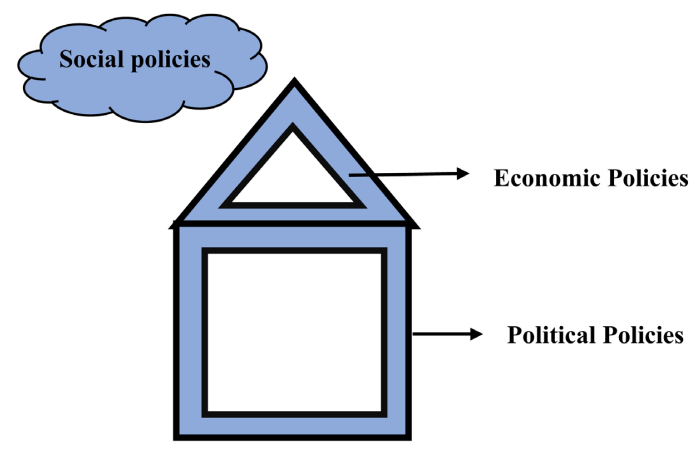

(a)

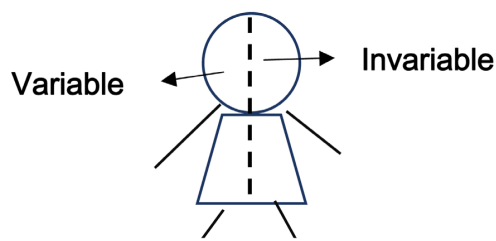

(b)

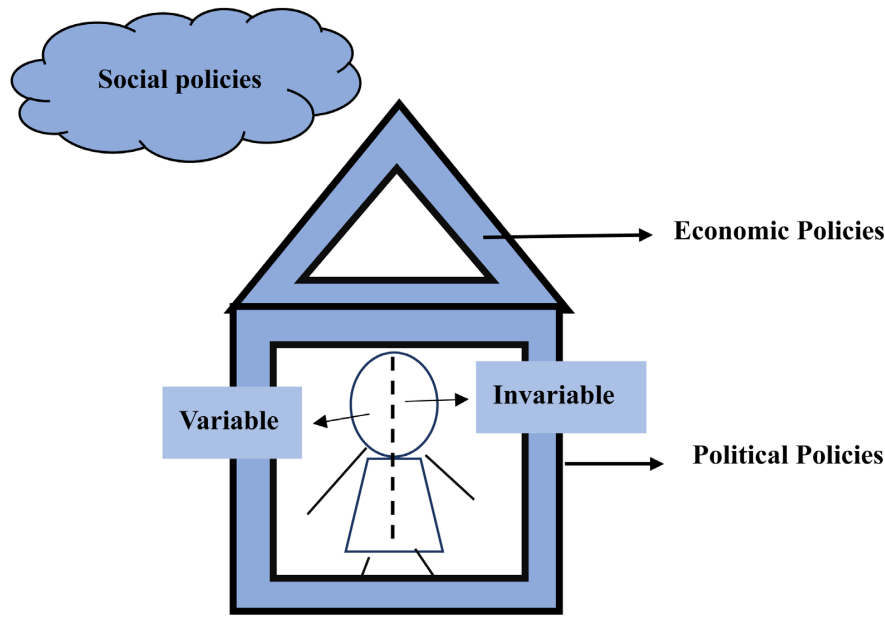

(c)

Figure 1. (a) Utopia model of space-dimension-Archeological or house model; (b) Utopia model of space-dimension-Ontological model; (c) Utopia model of spacedimension-Architectural model.

After knowing about the structure of human nature, human flourishing becomes the next concern. Human flourishing implies happiness. One of the most influential arguments is from Aristotle, who considers that human's flourishing achieved through "reason and virtue, through the exercise of their capabilities and the development of their potential" (qtd. in Levitas, 2013: p. 177). Besides, the freedom to be unhappy is essential for loss and longing, which is also involved in human flourishing. Since Levitas' paper does not introduce IROS model in detail, the more exhaustive argument is not mentioned in it.

The interdependent and interacting social institution in archeological mode (house mode) and the ontological mode compose a utopia model as architecture in which the relationship and balance between institution-creating and self-creating 
are primarily taken into concern.

This study suggests that the relation between the archeological and ontological is a symbiosis which is "a biological process that occurs when two entities enjoy mutual dependence and mutual benefit" (Levitas, 2013: p. 41).

The constitution of archeological utopia "draft" provides a proper external world for human flourishing in ontological mode. In return, the development of the human condition can contribute to the better construction of social institutions.

However, a utopian mode has been misunderstood as a final production of a blueprint and been disputed by some scholars for several decades. This misrepresent reveals the time feature of utopia and leads to the discussion on utopia's time dimension.

\section{Utopia Model of Time-Dimension}

Until now, a utopia refers to an imaginary better society in the future but numerous scholars misrepresent that utopia is a static blueprint. This misunderstanding accompanies more misinterpretations that utopia is "perfection pursing” (Sargisson, 2007: p. 27), radical and totalitarian (Talmon, 1961; Schapiro, 1972; Popper, 2013). In contrast, other utopia scholars refute their misunderstanding by proposing the nature of utopia as "temporal” (Wegner, 2007: p. 125), "unstable, open” (Žižek, 1989: p. 135), “dynamic” (Moylan, 1986). Thus, utopia is not a perfect blueprint that requires radical change and totalitarianism.

So far, our utopian method has been developed as a dynamic one. Nevertheless, how does it transform remained unclear. To solve this problem, I learned from Raffaella Baccolini's paper "Finding Utopia in Dystopia: Feminism, Memory, Nostalgia, and Hope" in this book, and bricolages nostalgia, memory and utopia into a dynamic process model which can be synthesized with the three-dimension utopian model and transformed into a four-dimension utopian model.

Kenneth Roemer (2007) addresses that one should develop "the capacity to measure the present, the past by contrasting them to imaginings of the alternative world" (Roemer, 2007: p. 133) to analyze utopian works. Although he mentions the necessity of exploring a utopian world concerning the past, the present and the future, he fails to explain the relations between the three. While some scholars raise their arguments to detail the relationships through connections between the concepts of memory, forgetting, nostalgia, and utopia. Based on that, I developed the Utopia Model of Time-Dimension (see Figure 2).

The becoming of utopia is based on the dynamic reflection on the past and the present. Memory is a process that can revise ${ }^{1}$ the past-present situation and pave a new way for alternative societies. Thus, the processing of memory becomes the primary part of utopia construction.

${ }^{1}$ According to Adrienne Rich, revise is the act of looking backward with fresh perspectives. Rich, Adrienne. "When we dead awaken: Writing as re-vision." College English 34.1 (1972): 18-30. 


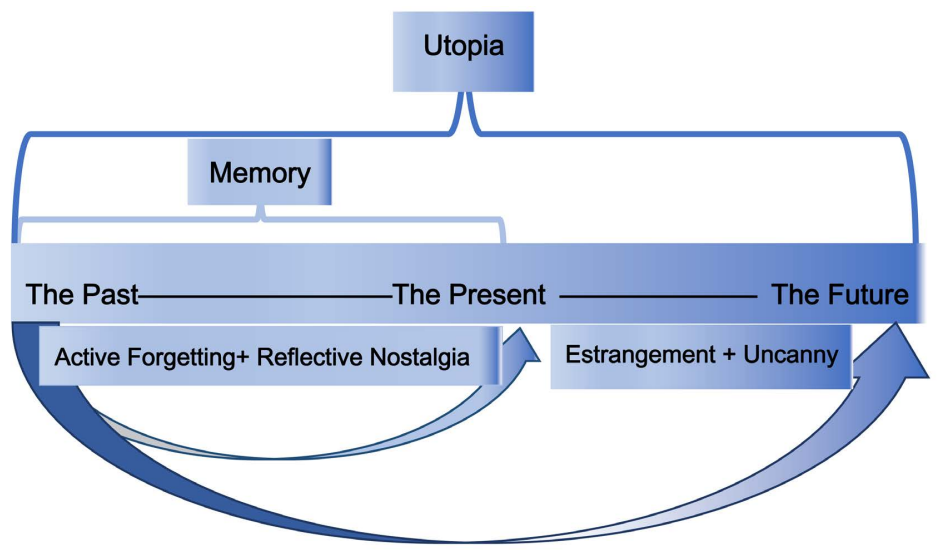

Figure 2. Utopia model of time-dimension.

Memory is a "repository of experience and value" (Baccolini, 2007: p. 170). It has been classified into less valuable memory: a simpler recall, and "a highly functional memory that is instrumental for an understanding of the past and the future" (Baccolini, 2007: p. 170). The former is identified as anamnesis ${ }^{2}$ (recollection), which is "conservative and precludes new knowledge since all knowledge lies in the past" (Baccolini, 2007: p. 170). In contrast, the highly functional memory involves anagnorisis (recognition) with which memory is reactivated in the present as a novel and interacting product of the past and the present. To avoid repetitive historical problems and catalyze a positive change in the future, it is necessary to choose the highly functional memory.

The primary step in processing memory is "active forgetting" (from Nietzsche), which refers to pruning and selecting memory to open up the new possibility. Since memory is functioned as contributing to a hopeful future with redemptive power (Benjamin, 1992), memories that flash up at a moment of danger should be seized, including the "histories of the oppressed, the marginalized and the dispossessed" (Baccolini, 2007). Otherwise, they can disappear silently and irretrievably and thus spread the injustice and other social problems into the future and "foreclose the possibility for change" (Baccolini, 2013: pp. 118-119). Then, "a critical, reflective, and progressive nostalgia is responsible for using the past in a dialectical way to change and illuminate present conditions which might lead to social change" (Lichtenstein, 2001: p. 217). That is the memory processing, the first process of the Utopian Model of Dimension.

After that, the approaches of estrangement and uncanny will be employed in the following process of utopia becoming. People might not draw too much attention to the familiar situations since they are so common. However, things become different if familiar things are revealed in an unfamiliar or subversive way. That is the mechanism of estrangement and uncanny. Although people know the uncanny part is unfulfilled at present, the estranged components re-

${ }^{2}$ This term is rasied by Ernst Bloch and cited from Geoghegan, Vincent. (1990) "Remembering the Future." Utopian Studies 1.2: 52-68.

${ }^{3}$ Ibid. 2. 
mind them that the alternative possibilities in the future can be expected and strive for.

\section{A Time-Space Utopian Model}

In the above two parts, the spatial utopian model and the time-based utopian model have been devised. However, utopia is a time-space concept that indicates the two model should be combined to display the utopian society dynamically (see Figure 3).

Figure 3 is the fitting sketch of the time-space utopia model. As the becoming of utopia is a dynamic process, all elements in "house mode" and ontological mode are transforming as time goes by. The gradual change of color stimulates the dynamic process in a simple way. Besides, every part of this model might undergo a course of reflecting on the past, concerning the present, and looking into the future through estrangement. During this process, elements might interact with each other in distinct degrees, influencing the becoming of utopia. Nevertheless, figuring out how the process of interaction is beyond the discussion of this study.

Except for the literary-critical tool (the time-space utopian model), this book also contains some illuminating approaches to selecting reading materials when doing utopia-related research. Specifically, Gregory Claeys (2007) proposes the five stages of the modern British utopianism process through reading and analyzing modern British utopian literature, academic monographs and history books. His methods contribute to the broad selections of reading lists, but he fails to explain how to do further selective analysis. Kenneth M. Roemer (2007) devises a three-level method to specify the reading, and analyzing scope when exploring a theme of utopian works from a particular region in specific periods. First, he uses literature as a culture index by the nature and popularity of

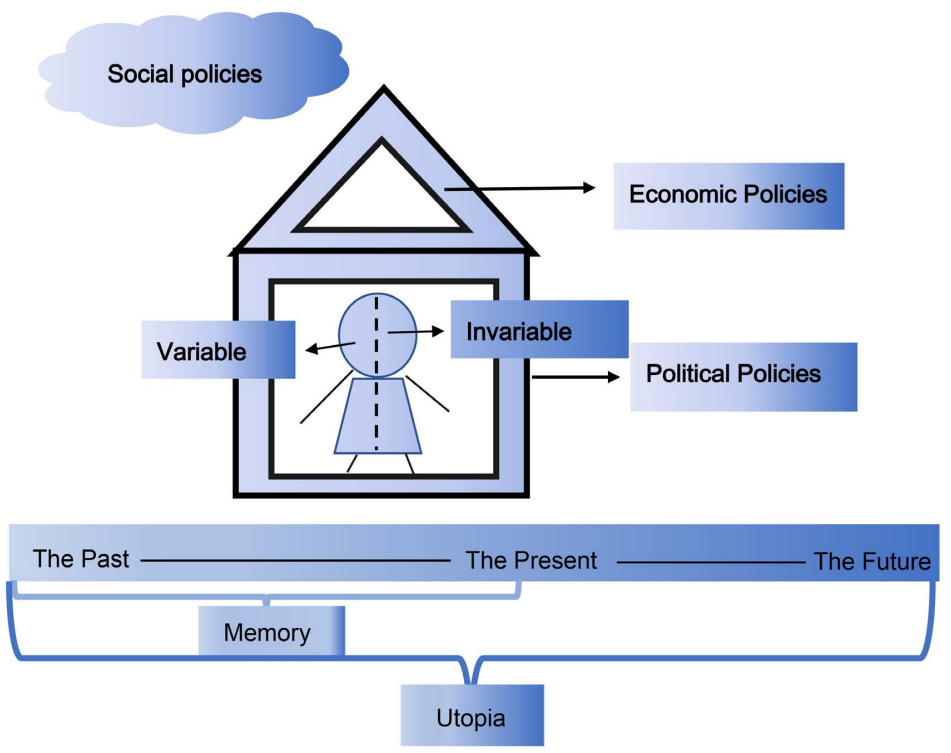

Figure 3. Utopia of time-space dimension. 
utopian literature (Roemer, 2007). Then, the method is applied in three steps, "a content analysis of the entire sample, examinations of the most popular works, and of the most complex works which well-known authors sometimes wrote, but often by obscure authors" (Roemer, 2007: p. 134). This three-level method "avoids hasty generalities" and "simplistic portraits of utopian literature" (p. 136).

Those approaches can contribute to the selection of reading materials in an exploration of the becoming of utopian process in other regions and in other times.

\section{Conclusion}

This book mainly provides us with a sense of the time-space dimension of utopian methods and techniques of selecting research materials that can be applied in examining the process of utopia becoming in a particular region during a given time. Although given the length of papers, complete theories of the utopian scholars in this book cannot be displayed, and their academic frameworks and ideas can be concerned as guidance for interested readers to explore further.

Additionally, the authors of this book also mention their personal experiences from junior researchers to mature scholars in utopian fields. Thus, readers might get to know how the utopian scholars become involved in utopian projects, and they might make self-reflection whether they will devote themselves to this interdisciplinary field. Besides, readers of this book might discover some similarities they share with the utopian scholars. For example, both lived in multi-cultural circumstances and majored in more than one subject when they were young. They even shared the same interest in reading fantasies when they were kids. Indeed, these are my similarities with utopian scholars of this book. After realizing that, I become more aware of why I am here and get more determined in devoting myself to utopian fields.

When it comes to the scope of readers, this book is suitable for anyone interested in utopian studies, especially for those who would like to apply utopia as a method or philosophy to solve problems, whether in social science or literary criticism fields.

\section{Conflicts of Interest}

The author declares no conflicts of interest regarding the publication of this paper.

\section{References}

Baccolini, R. (2007). Finding Utopia in Dystopia: Feminism, Memory, Nostalgia, and Hope. In T. Moylan, \& R. Baccolini (Eds.), Utopia Method Vision: The Use Value of Social Dreaming (pp. 159-190). Peter Lang Publishing.

Baccolini, R. (2013). "A Useful Knowledge of the Present Is Rooted in the Past": Memory and Historical Reconciliation in Ursula K. Le Guin's the Telling. Routledge.

Benjamin, W. (1992). These on the Philosophy of History. In H. Zohn (Ed.), Illuminations (pp. 245-255). Fontana. 
Claeys, G. (2007). Rethinking Modern British Utopianism: Community and the Mastery of Desire. In T. Moylan, \& R. Baccolini (Eds.), Utopia Method Vision: The Use Value of Social Dreaming (pp. 87-111). Peter Lang Publishing.

Geoghegan, V. (1990). Remembering the Future. Utopian Studies, 1, 52-68.

Kincheloe, J. L., McLaren, P., \& Steinberg, S. R. (2017). Critical Pedagogy and Qualitative Research. In The SAGE Handbook of Qualitative Research (pp. 418-464). SAGE.

Levitas, R. (2007). The Imaginary Reconstruction of Society. In T. Moylan, \& R. Baccolini (Eds.), Utopia Method Vision: The Use Value of Social Dreaming (pp. 47-68). Peter Lang Publishing.

Levitas, R. (2013). Utopia as Method: The Imaginary Reconstitution of Society. Springer. https://doi.org/10.1057/9781137314253

Lichtenstein, T., \& Bellmer, H. (2001). Behind Closed Doors: The Art of Hans (Vol. 9). University of California Press.

Marin, L. (1984). Utopics: The Semiological Play of Textual Spaces.

Moylan, T. (1986). Demand the Impossible: Science Fiction and the Utopian Imagination (Vol. 943). Taylor \& Francis.

Popper, K. R. (2013). The Open Society and Its Enemies. Princeton University Press. https://doi.org/10.1515/9781400846672

Roemer, K. M. (2007). More Aliens Transforming Utopia: The Futures of Reader Response and Utopian Studies. In T. Moylan, \& R. Baccolini (Eds.), Utopia Method Vision: The Use Value of Social Dreaming (pp. 131-158). Peter Lang Publishing.

Sargisson, L. (2007). The Curious Relationship between Politics and Utopia. In T. Moylan, \& R. Baccolini (Eds.), Utopia Method Vision: The Use Value of Social Dreaming (pp. 25-46). Peter Lang Publishing.

Schapiro, L. (1972). Totalitarianism. Pall Mall.

Talmon, J. L. (1961). The Origins of Totalitarian Democracy.

Wegner, P. (2007). Here or Nowhere: Utopia, Modernity, and Totality. In T. Moylan, \& R. Baccolini (Eds.), Utopia Method Vision: The Use Value of Social Dreaming (pp. 113-129). Peter Lang Publishing.

Žižek, S. (1989). The Sublime Object of Ideology. Verso Books. 